
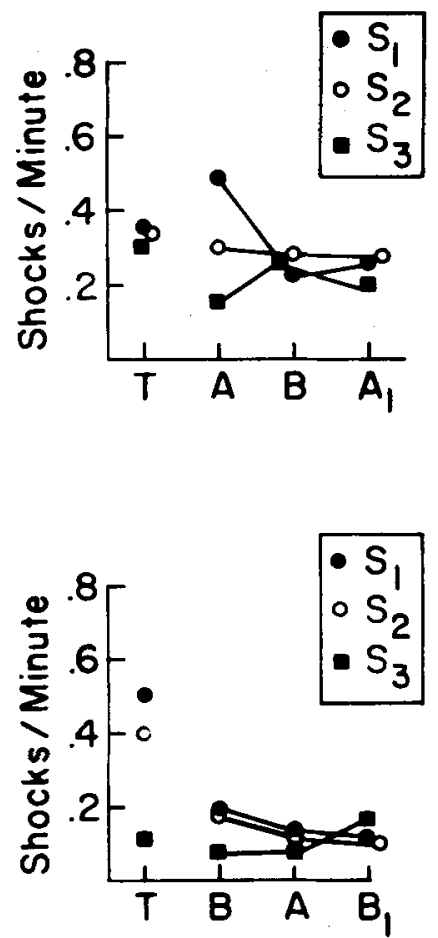

Fig. 2. Shock rates for the last training session ( $T$ ), and mean shocks per minute over four sessions over successive 30-min periods. A, feedback condition; B, feedback removed.

proprioceptive-result in a generalization decrement. Accordingly, the transition from Condition $T$ to $B$, and from $A$ to $B$, would be expected to result in a decline of response rates. Neither prediction was supported by the results of this experiment since neither condition resulted in a decline of responding; on the contrary, Condition $\mathrm{BAB}_{1}$ led to an increase of response rate, while response rate under Condition $\mathrm{ABA}_{1}$ was maintained.

The following analysis is presented in explanation of our results. In an FOA situation, the response-produced stimulus signals a "safety" period during and following which a $S$ tends not to respond (Anger, 1963; Rescorla, 1968) so that the total response rate is reduced. An FS, therefore; acts as a stimulus for "response pacing." Under Condition $\mathrm{BAB}_{1}$, where the pacing stimulus is absent at the start, FOA performance may deteriorate, resulting in an increase of shock and leading the $S$ to increase his response rate. The subsequent high rate of response as a consequence of being shocked (Sidman, 1958) would be expected to maintain itself since it leads to avoidance. During the period of $\mathrm{ABA}_{1}$, the $S$ seems to maintain the rate of response developed under $\mathbf{A}$, and would probably only change this rate if major rather than supportive stimulus changes occurred during the session. By implication, we regard the enhanced feedback stimulus as supportive of a response rate, rather than its primary determinant. This function must be attributed to the parameters of the avoidance schedule.

In general, the results of this experiment support the proposition that, with extensive training, a $S$ relies less and less upon external and proprioceptive stimuli in the maintenance of a conditioned rate of response. Changes in response feedback made in the early part of a session, at a time when the pattern of responding for that session is developing, i.e., during the "warm-up" period, may affect the rate for the remainder of the session, provided it does not interfere with avoidance. In short, across-session behavior (as from $\mathrm{T}$ to $\mathrm{B}$ ) rather than within-session behavior (as from $A$ to B) seems to be effected by manipulations of the feedback stimulus.

\section{REFERENCES}

ADAMS, J. A. Response feedback and learning. Psychological Bulletin, 1968, 70, 486-504.

ANGER, D. The role of temporal discrimination in the reinforcement of Sidman avoidance behavior. Journal of the Experimental Analysis of Behavior Supplement, 1963,6, 477-506.

BOLLES, R. C., \& GROSSEN, N. E. Effects of an informational stimulus on the acquisition of avoidance behavior in rats. Joumal of Comparative \& Physiological Psychology, 1969, 68,90-99.

BOLLES, R. C., \& POPP, R. J. Parameters affecting the acquisition of Sidman avoidance. Journal of the Experimental Analysis of Behavior, 1964, 7, 315-321.

BOLLES, R.C., \& WARREN, J. A. The acquisition of bar-press avoidance as a function of shock intensity. Psychonomic Science, 1965, 3, 397-398.

LEAF, R. C. Acquisition of Sidman avoidance responding as a function of S-S interval. Journal of Comparative \& Physiological Psychology, $1965,59,298-300$.

LEAF, $R$. C. Some effects of response consequences on Sidman avoidance acquisition Journal of Comparative \& Physiological Psychology, 1966, 61, 217-220.

RESCORLA, R. A. Pavlovian conditioned fear in Sidman avoidance learning. Journal of Comparative \& Physiological Psychology, 1968, 65, 55-60.

SANDLER, J., DAVIDSON, R. A., \& HOLZSCHUH, R. D. Effects of increasing punishment intensity on Sidman avoidance behavior. Psychonomic Science, 1966, 5 , 103-104.

SIDMAN, M. Some notes on "bursts" in free-operant avoidance experiments. Journal of the Experimental Analysis of Behavior, 1958, 1, 167-172.

\section{NOTE}

1. This research was supported by NSF Grant GB-8505.

\title{
Some effects of scopolamine on locomotor activity in rats
}

BARTON MEYERS and ROBERT $C$. WILCHIN, Brooklyn College of the City University of New York, Brooklyn, N.Y. 11210

On 2 consecutive days, rats $(N=30)$ were injected subcutaneously with saline, $0.2 \mathrm{mg} / \mathrm{kg}$ methscopolamine, or $0.2 \mathrm{mg} / \mathrm{kg}$ scopolamine, and tested for their levels of locomotor activity. Scopolamine produced hyperactivity on both days, while methscopolamine induced no effect different from that of saline. These results were discussed in relation to the suggestion of Calhoun \& Smith (1968) that scopolamine impairs passive avoidance due to its effect on activity.

The systemic circulation of muscarinic cholinergic blocking drugs, such as atropine and scopolamine, increases the locomotor activity of both mice (Harris, 1961; Tripod, 1957) and rats(Meyers, Roberts, Riciputi, \& Domino, 1964; Payne \& Anderson, 1967; Pradham \& Roth, 1968; Tapp, 1965). Similarly, these agents, if injected at a time calculated to produce peak effects during training, impair passive avoidance behaviors in both mice (Bohdanecký \& Jarvik, 1967; Calhoun \& Smith, 1968; Stark, 1967) and rats (Bignami \& Gatti, 1968; Burešová, Bureš, Bohdanecký, \& Weiss, 1964; Meyers, 1965; Meyers \& Lazarus, 1967). Conversely, if the peak effect occurs shortly after the trial, i.e., during the presumed consolidation period, no passive-avoidance deficit results (Bohdanecký \& Jarvik, 1967; Burešová et al, 1964; Calhoun \& Smith, 1968).

Data such as these have led Calhoun \& Smith (1968) to conclude that anticholinergic agents exert their effect on the performance of passive avoidance, rather than on the learning of it. Specifically, they have suggested that scopolamine makes Ss "more excitable" or "more active" and that this condition impairs their ability to withhold the appropriate response in the passive-avoidance situation.

However, it has been demonstrated that the passive-avoidance behavior of rats can become impervious to repeated administrations of scopolamine (Bignami \& Gatti, 1968; Meyers, 1965; Meyers \& Lazarus, 1967). If successive scopolamine injections should continue to increase locomotor activity, though, it would be 


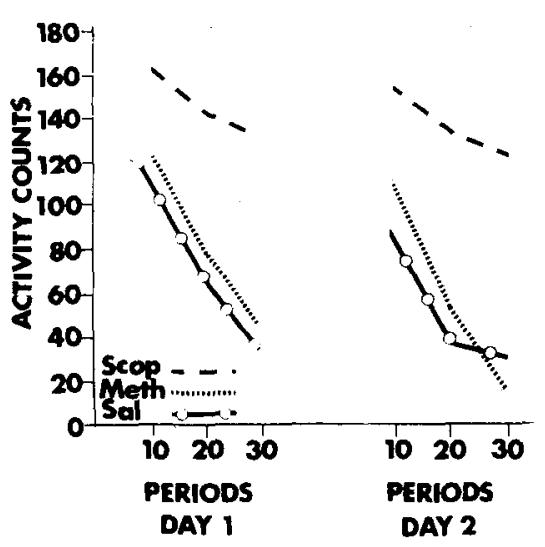

Fig. 1. Photobeam interruptions recorded as activity counts at three 10 -min intervals for 2 consecutive days for rats injected subcutaneously with saline, $0.2 \mathrm{mg} / \mathrm{kg}$ scopolamine, or $0.2 \mathrm{mg} / \mathrm{kg}$ methscopolamine.

obvious that no necessary relationship holds between the scopolamine effects on activity and on passive avoidance. This experiment investigated that relationship by studying the effect on locomotor activity of repeated scopolamine administration under conditions highly similar to those which have previously been shown to produce the "behavioral tolerance" effect on passive avoidance (Meyers, 1965; Meyers \& Lazarus, 1967).

\section{SUBJECTS}

Thirty male rats of the Wistar strain (Albino Farms, Red Bank, New Jersey), allowed free access to food and water and ranging in weight from 218 to $288 \mathrm{~g}$ at the beginning of the experiment, were assigned randomly with the restriction of equal numbers to three groups: (1) saline, (2) methscopolamine, and (3) scopolamine. APPARATUS

The experimental chambers, which were enclosed in separate sound-reducing compartments with ventilation but without illumination, were two identical boxes $(23.5 \times 29.0 \times 14.0 \mathrm{~cm})$ corstructed of Plexiglas and with a grid floor. Two photobeams (Lehigh Valley Electronics) trisected each box parallel to its short side. If $S$ interrupted a photobeam, a count was recorded. These counts were recorded separately during the three consecutive 10 -min periods which constituted a $30-\mathrm{min}$ session. The recording of responses and the timing of experimental intervals were automatically controlled by relay circuitry in conjunction with counters and clocks which were located in a room adjacent to that containing the experimental chambers.

\section{PROCEDURE}

Each $S$ received his experimental sessions at approximately the same time of day on 2 consecutive days. One-half hour prior to each session, $\mathrm{S}$ was injected with the agent appropriate to his group. Scopolamine hydrobromide and methscopolamine bromide (Pamine) ${ }^{2}$ were given as base in the dose of $0.2 \mathrm{mg} / \mathrm{ml}$. All injections were given subcutaneously and had a volume of $1.0 \mathrm{ml} / \mathrm{kg}$.

\section{RESULTS}

The findings are displayed in Fig. 1. Statistical comparisons ${ }^{3}$ demonstrated significant drug and time-period effects on both Days 1 and 2. In addition, the Drug by Period interactions for both days reached statistical significance. Since the saline and methscopolamine groups differed for only one 10-min period (the second period on Day 1), while the scopolamine group was significantly more active than both of those groups during all periods on both days, it is clear that the drug effect resulted from the hyperactivity of the scopolamine group. The fact that for all groups on both days the activity count during the last 10 -min period was significantly lower than that for the first $10 \mathrm{~min}$ period indicates that the period effect was produced by a decline in activity over time. It is presumed that the flatter slope of the activity gradient on both days of the scopolamine group accounted for the significant Drug by Period interactions effect. Finally, the saline and methscopolamine control groups were less active on Day 2 relative to Day 1 , but no such difference obtained for the scopolamine group.

\section{DISCUSSION}

The major finding of this study is that scopolamine-treated Ss displayed elevated activity levels on 2 consecutive days. Since it has been shown under highly similar conditions that rats injected with scopolamine suffer no passive-avoidance deficit on the second of 2 consecutive training days (Meyers, 1965; Meyers \& Lazarus, 1967), it should be clear that there is no necessary relationship between the effects of hyperactivity and impaired passive avoidance produced by this drug. Thus, the hypothesis of Calhoun \& Smith (1968), suggesting such a relationship, must be rejected.

In addition, the results confirm the previous findings that cholinergic blocking agents increase locomotor activity and, since the peripheral blockade produced by methscopolamine was without effect, that their site of action is a central one (Harris, 1961; Meyers et al, 1964; Payne \& Anderson, 1967; Pradham \& Roth, 1968; Tapp, 1965;Tripod, 1957).

Finally, the fact that the scopolamine group seemed to show a lesser decline in activity within days and no decline over days might be interpreted as evidence that the drug retards habituation to a novel environment. If so, these results support the habituation hypothesis of Carlton (1965).

\section{REFERENCES}

BIGNAMI, G., \& GATTI, G. L. Repeated administration of centra anticholinergics-classical tolerance phenomena versus behavioral adjustments to compensate for drug-induced deficits. Paper presented at meeting of the European Society for the Study of Drug Toxicity, Oxford, England, April 1968

BOHDANECKÝ, Z., \& JARVIK, M. E. Impairment of one-trial passive avoidance leaming in mice by scopolamine, scopolamine methylbromide, and physostigmine. International Journal of Neuropharmacology, $1967,6,217-222$

BUREŠOVÁ, O., BUREŠ, J. BOHDANECKÝ, Z., \& WEISS, T. Effect of atropine on learning, extinction, retention and retrieval in rats. Psychopharmacologia (Berlin), 1964, 5, 255-263.

CALHOUN, W. H., \& SMITH, A. A. Effects of scopolamine on acquisition of passive avoidance. Psychopharmacologia (Berlin), 1968, 13, 201-209.

CARLTON, P. L. The hippocampus, brain-acetylcholine and habituation. Paper presented at the symposium on brain biochemistry and behavior, American Association for the Advancement of Science meeting, Berkeley, December 1965.

HARRIS, L. S. The effect of various anti-cholinergics on the spontaneous activity of mice. Federation Proceedings, 1961, 20, 395. (Abstract)

MEYERS, B. Some effects of scopolamine on a passive avoidance response in rats. Psychopharmacologia (Berlin), 1965, 8, 111-119.

MEYERS, B., \& LAZARUS, M. A. Diminished responsivity on a passive avoidance task to second administration of scopolamine. Psychological Reports, 1967, 20, 175-178.

MEYERS, B., ROBERTS, K. H., RICIPUTI, R. H. \& DOMINO, E. F. Some effects of muscarinic cholinergic blocking drugs on behavior and the electrocorticogram. Psychopharmacologia (Berlin), 1964, 5, 289-300.

PAYNE, R., \& ANDERSON, D. C. Scopolamine-produced changes in activity and in the startle response: Implications for behavioral activation. Psychopharmacologia (Berlin), 1967, 12, 83-90.

PRADHAM, S. N., \& ROTH, T. Comparative behavioral effects of several anticholinergic agents in rats. Psychopharmacologia (Berlin), $1968,12,358-366$.

STARK, L. G. The inability of scopolamine to induce state-dependent one-trial learning. Federation Proceedings, 1967, 26, 613. (Abstract)

TAPP, J. T. Cholinergic mechanisms in operant responding. Journal of Comparative \& Physiological Psychology, 1965, 59, 469-472. TRIPOD, J. Caracterisation generale des effets pharmacodynamiques de substances psychotropiques. In S. Garattini and V. Ghetti (Eds.), Psychotropic drugs. Amsterdam: Elsevier, 1957. Pp. 437-447.

$$
\text { NOTES }
$$

1. Research supported in part by USPHS Grant MH 10897.

2. Supplied by the Upjohn Co., Kalamazoo, Mich.

3. All comparisons of more than two groups employed an analysis of variance of repeated measures. Tests performed between two groups used two-tailed $t$ tests. The reported presence or absence of differences hinged on the 0.05 level of significance. 